\title{
Microwave coagulation using a perfusion microwave electrode: Preliminary experimental study using ex vivo and in vivo liver
}

\author{
HIDETO UMEHARA, TOSHIHITO SEKI, RYOSUKE INOKUCHI, TORU TAMAI, \\ RINAKO KAWAMURA, TOSHIKI ASAYAMA, KOZO IKEDA and KAZUICHI OKAZAKI \\ Department of Gastroenterology and Hepatology, Kansai Medical University, Moriguchi, Osaka 570-8507, Japan
}

Received September 21, 2011; Accepted October 13, 2011

DOI: $10.3892 /$ etm.2011.380

\begin{abstract}
To assess the coagulation capability of a perfusion microwave electrode (PME) as a key component of microwave coagulation therapy, a preliminary experimental study was performed using ex vivo and in vivo livers. For a microwave electrode, a PME was employed. Using a PME, saline was passed through the electrode and injected continuously into the target tissue. Using an ex vivo bovine liver, the range of tissue coagulation was measured for various volumes of infused saline and microwave outputs. Using an in vivo porcine liver, the efficiency of coagulation by a PME was compared with that of radiofrequency ablation (RFA) using a cool-tip needle. In an ex vivo bovine liver, the range of tissue coagulation increased as the flow rate of saline increased. In the in vivo porcine liver, the range of coagulation was similar to that found in the ex vivo bovine liver. With a PME under conditions of a microwave output of $80 \mathrm{~W}$, a flow rate of $3 \mathrm{ml} / \mathrm{min}$ and irradiation time of $5 \mathrm{~min}$, the range of coagulation was $44.8 \pm 2.8 \mathrm{~mm}$ [maximum vertical diameter: (a)] x 31.2 $\pm 2.4 \mathrm{~mm}$ [maximum transverse diameter: (b)]. The range of RFA (cool-tip needle) at $12 \mathrm{~min}$ was $46.0 \pm 2.0 \mathrm{~mm}$ (a) $\times 30.2 \pm 2.0 \mathrm{~mm}$ (b). With only $5 \mathrm{~min}$ of microwave irradiation, the use of a PME enabled induction of the same range of coagulation that was obtainable by RFA for 12 min. In comparison with microwave coagulation without saline infusion, the use of a PME made it possible to extend the range of tissue coagulation to a range equal to that of RFA in a short time. Microwave coagulation using a PME may be one of the suitable tissue coagulation systems for local ablation treatment.
\end{abstract}

Correspondence to: Dr Toshihito Seki, Department of Gastroenterology and Hepatology, Kansai Medical University, 10-15 Fumizonocho, Moriguchi, Osaka 570-8507, Japan

E-mail: sekit@takii.kmu.ac.jp

Key words: perfusion microwave electrode, microwave coagulation, radiofrequency ablation

\section{Introduction}

Over the past two decades, owing to advances in various imaging techniques, small hepatocellular carcinomas (HCCs) have been detected (1). Percutaneous ethanol injection therapy (PEIT) (2-6), percutaneous microwave coagulation therapy (PMCT) (7-11) and percutaneous radiofrequency ablation (PRFA) (12-14) are minimally invasive ablation procedures that are used to treat such small tumors at numerous institutions. PEIT, which was the first to become more widely used owing to its low cost and convenience, has certain disadvantages, including insufficient local control owing to the efflux of ethanol into the blood vessels, and the inadequate diffusion of ethanol due to the presence of a fibrous capsule or septum in tumors $(5,6)$.

To overcome these disadvantages of PEIT, thermal ablation treatments, such as PRFA and PMCT, were developed and offered local control that is better than that of PEIT $(10,13)$. At present, PRFA is employed more commonly for local therapy since the range of tissue coagulation achieved by a single puncture is larger with PRFA than with PMCT. Therefore, a new type of microwave electrode was designed to overcome this disadvantage of conventional PMCT. This new type of microwave electrode is a perfusion microwave electrode (PME), which continuously supplies a solution to target tissues and provides continuous and stable heat. In contrast to a conventional microwave system, this system may expand the range of coagulation.

To evaluate the coagulation capability of a PME as a key component of microwave coagulation therapy, the present preliminary experimental study was conducted.

Using an ex vivo bovine liver, the range of tissue coagulation was measured for various volumes of infused saline and microwave outputs. The efficiency of coagulation using the PME was then compared with that using an RFA electrode (cool-tip needle) in an in vivo porcine liver.

\section{Materials and methods}

Coagulation experiments on an ex vivo bovine liver and an in vivo porcine liver were conducted using the PME. The system employs a microwave generator (Microtaze AZM-520; Alfresa-Pharma, Osaka, Japan), which produces microwaves at $2450 \pm 50 \mathrm{MHz}$, to be transmitted to the electrode via a 
coaxial cable. During microwave irradiation, thermal coagulation is induced in the tissue by dielectric heating at the tip of the electrode. PME is $14 \mathrm{G}$ in diameter and $25 \mathrm{~cm}$ in length. The electrode has three rectangular side holes (each measuring $1 \times 2 \mathrm{~mm}$ ) at a position $15 \mathrm{~mm}$ from the tip of the electrode. A perfusion solution flows out in three directions through these holes (Fig. 1). The solution is injected into the electrode through an injection port located near the electrode connector. Infusion is performed using a pump that permits the rate of infusion to be changed appropriately.

Coagulation of an ex vivo bovine liver. When an ex vivo bovine liver was coagulated using the PME, physiological saline was injected (isotonic sodium chloride, Physisalz-PL, $0.9 \% \mathrm{w} / \mathrm{v}$ sodium chloride; Fuso Pharmaceutical Industries, Osaka, Japan). The flow rate was set at $0,1,2,3,4$ or $5 \mathrm{ml} / \mathrm{min}$ ( $\mathrm{n}=5$ for each). Saline was injected using a pump (TE-161S, Terumo, Tokyo, Japan). A flow rate of saline $>6 \mathrm{ml} / \mathrm{min}$ results in an overflow that exits to the surface of the liver through the insertion line. Therefore, the upper limit of the saline flow rate was set at $5 \mathrm{ml} / \mathrm{min}$. A physiological saline solution at room temperature (approximately $25^{\circ} \mathrm{C}$ ) was used for infusion.

In the present study, the microwave output was set at 60 or $80 \mathrm{~W}$ and the microwave irradiation time at $5 \mathrm{~min}$. According to the manufacturer, $5 \mathrm{~min}$ is optimal for obtaining the maximal coagulated area by a conventional microwave electrode. In reality, clinical microwave coagulation therapy is performed under these power levels and irradiation time in Japan.

To confirm whether the temperature sufficient for tissue coagulation was continuously maintained, the temperature of the tissue at the tip of the electrode was measured during microwave irradiation at 1-min intervals. Moreover, the temperature of the electrode at a position $5 \mathrm{~cm}$ from the tip was measured to confirm whether the temperature rose excessively at the shaft of the electrode.

A portable thermocouple thermometer (PTC-201; Unique Medical, Tokyo, Japan) and cannula-type temperature sensors (PTI-200; Unique Medical) were employed. The sensors were attached to the tip of the electrode and to the shaft $(5 \mathrm{~cm}$ from the tip).

The range of tissue coagulation was measured as the maximum vertical diameter (a) and maximum transverse diameter (b) of the largest coagulated area observed in the liver sections that were cut out following microwave irradiation.

The portion showing a clear discoloration (white zone) that had been induced by microwave irradiation was judged to be a coagulated area and a vaguely discolored portion, a non-coagulated section. The range was measured for the clearly discolored section only.

Coagulation of in vivo porcine liver. Using healthy pigs, in compliance with the Guidelines for Animal Experiments of Kansai Medical University (Japan), the following protocol was prepared for this study. The protocol was approved by the Animal Experimentation Committee, Kansai Medical University. The animals were handled according to the guidelines of the National Institutes of Health (Guide for the Care and Use of Laboratory Animals, NIH publication no. 90-23, revised 1990).
For the experiment in in vivo porcine liver, live pigs weighing approximately $40 \mathrm{~kg}$ were used (liver weight, approximately $950 \mathrm{~g}$ ). Under light anesthesia induced by an intramuscular injection of ketamine hydrochloride (Ketalar for intravenous injection, 200 mg; Daiichi Sankyo, Tokyo, Japan) at a dose of $500 \mathrm{mg}$, endotracheal intubation was performed (Traquilon; inner diameter $7.0 \mathrm{~mm}$, outer diameter $9.3 \mathrm{~mm}$; 28 Fr Terumo, Tokyo, Japan). The tube was connected to a respirator (Model 55-0715; Harvard Apparatus, MA, USA). The frequency of respiration and tidal volume were set at $20 \mathrm{~min}$ and $15 \mathrm{ml} / \mathrm{kg}$, respectively. An animal anesthesia apparatus was used (SN-487; Shinano Manufacturing, Tokyo, Japan) and anesthesia was maintained with a mixture of gases (oxygen and air) and 0.5-5\% isoflurane (Isoful; Dainippon Sumitomo Pharma, Osaka, Japan). Under general anesthesia, a midline incision was made in the abdomen and the liver was identified. Coagulation was performed with the aid of an SSD-3500 ultrasonic apparatus (Aloka, Tokyo, Japan). The electrode was inserted under ultrasonic guidance to avoid major blood vessels and was placed at a depth of $5 \mathrm{~cm}$.

Microwave coagulation with the PME was performed with the infusion of physiological saline at an approximate temperature of $25^{\circ} \mathrm{C}$ at $3 \mathrm{ml} / \mathrm{min}$, a microwave output of $80 \mathrm{~W}$, and an irradiation time of $5 \mathrm{~min}$. On the basis of the experiment with the ex vivo bovine liver, it was decided that the aforenoted condition was efficient for an in vivo liver study. RFA was performed using a high-current $480 \mathrm{kHz}$ monopolar RF generator (CC-1-100; Radionics, Burlington, MA, USA) that was capable of a 2,000 mA (200 W) output. The electrode was equipped with a cool-tip RF system (Tyco Healthcare Japan, Tokyo), $25 \mathrm{~cm}$ in length, with a $3-\mathrm{cm}$ tip and an outer diameter of $17 \mathrm{G}$. Under general anesthesia, paired polar plates were attached to both hindlimbs of each pig. The application of RF energy was initiated with the generator in the impedancecontrol mode at the maximal output that is clinically required (approximately $120 \mathrm{~W}$ ).

RFA time was set at 5 and $12 \mathrm{~min}$. RFA was conducted for 5 min to compare it with the coagulation range of microwave irradiation, also conducted for $5 \mathrm{~min}$. The time recommended by the manufacturer for clinical use was $12 \mathrm{~min}$.

The range of tissue coagulation was measured in specimens that had been resected immediately following coagulation by both PME and RFA ( $n=5$ for each electrode type). The maximum vertical diameter (a) and the maximum transverse diameter (b) were measured for the largest coagulated area on the cut surface of the sections obtained from the liver where the electrode was inserted. The two methods were then compared. The portion showing a clear discoloration (white zone including the hemorrhagic rim) induced by microwave irradiation and RFA was judged to be the coagulated area in accordance with a previous report (15).

Statistical analysis. Statistical differences were identified using the parametric Student's t-test. $\mathrm{P}<0.01$ was considered to be statistically significant.

\section{Results}

Temperature measurement in the ex vivo bovine liver. As shown in Fig. 2, which displays the results of temperature measurement 


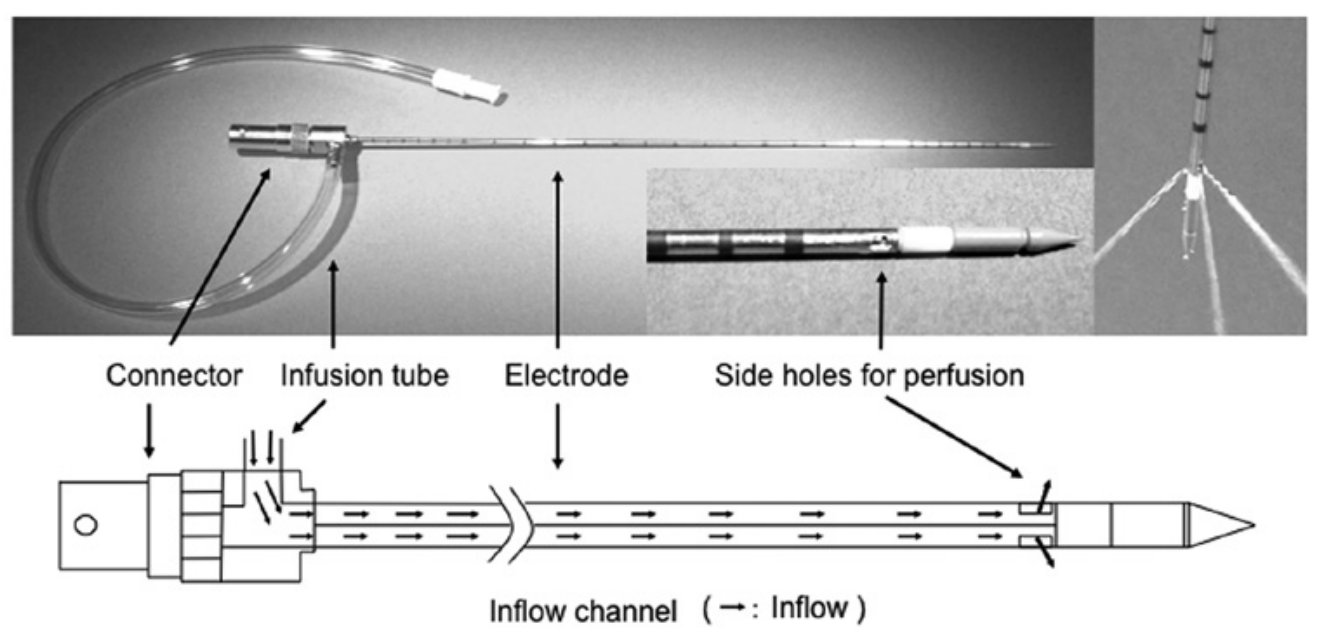

Figure 1. The lower view is an illustration of the perfusion microwave electrode (PME). The PME, $14 \mathrm{G}$ in diameter and $25 \mathrm{~cm}$ in length, has three rectangular side holes $(1 \times 2 \mathrm{~mm})$, positioned $15 \mathrm{~mm}$ from the tip of the electrode, through which the perfusion solution flows from the electrode in three directions. The solution is injected into the electrode through an injection port that is located near the electrode connector.
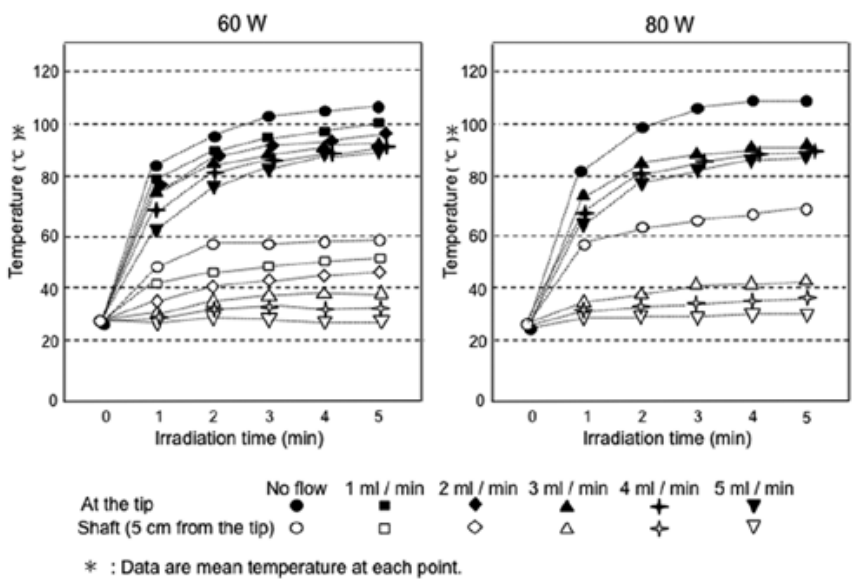

Figure 2. A change in temperature during microwave irradiation at the tip and temperature of the shaft, $5 \mathrm{~cm}$ from the tip using 60 and $80 \mathrm{~W}$. Measurements were not taken when the microwave output was $80 \mathrm{~W}$ and the flow rate was 1 or $2 \mathrm{ml} / \mathrm{min}$ since coagulated and carbonized tissue that adhered to the lateral port near the tip of the electrode interfered with reliable injection of the physiological saline.

during microwave irradiation, the tip of the electrode maintained a temperature that was sufficient for tissue coagulation $\left(>80^{\circ} \mathrm{C}\right)$ even when the physiological saline was injected. Meanwhile, the temperature increase in the electrode shaft was suppressed to $<45^{\circ} \mathrm{C}$ by perfusion of physiological saline through the electrode at flow rates of $3 \mathrm{ml} / \mathrm{min}$ or greater. Measurements were not taken under the conditions of a microwave output equal to $80 \mathrm{~W}$ and a flow rate of 1 or $2 \mathrm{ml} / \mathrm{min}$ since coagulated and carbonized tissue that adhered to the side holes of the electrode interfered with reliable injection of physiological saline.

Range of PME coagulation in the ex vivo bovine liver. Both the maximal vertical diameter (a) and maximal transverse diameter (b) were larger at $80 \mathrm{~W}$ than at $60 \mathrm{~W}(\mathrm{P}<0.05)$ (Fig. 3).

The range of coagulation increased when physiological saline was injected. Under conditions of a microwave output equal to $80 \mathrm{~W}$ with no flow, the range of tissue coagulation

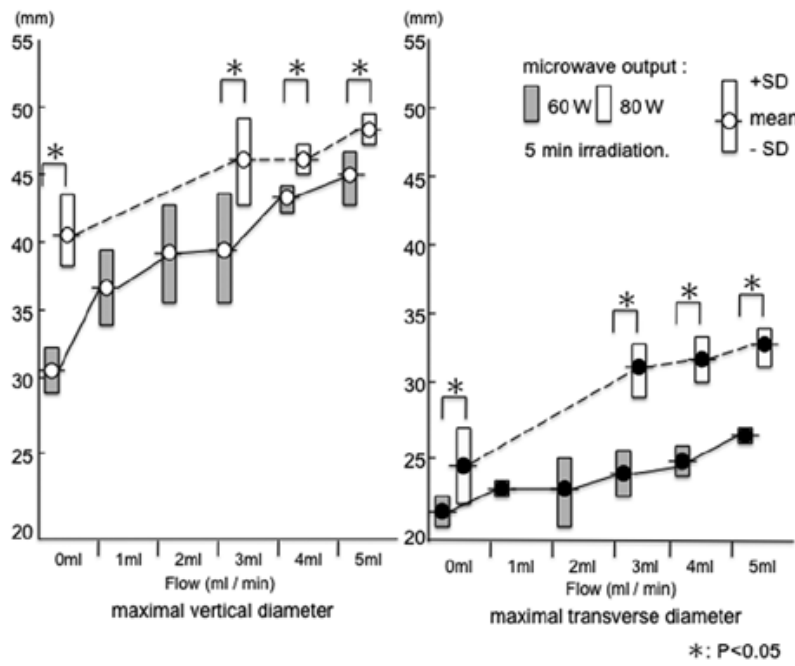

Figure 3. Range of PME coagulation in an ex vivo bovine liver. For each condition with no flow or with physiological saline injection, both the maximal vertical diameter and maximal transverse diameter were larger at 80 than at 60 W. SD, standard deviation; PME, perfusion microwave electrode.

was $41.8 \pm 2.5 \mathrm{~mm}$ (a) $\mathrm{x} 25.6 \pm 2.6 \mathrm{~mm}$ (b). When the microwave output was $80 \mathrm{~W}$ and the flow rates were 3,4 and $5 \mathrm{ml} / \mathrm{min}$, the range of tissue coagulation was $46.4 \pm 3.0 \mathrm{~mm}$ (a) $\times 32.2 \pm 1.8 \mathrm{~mm}$ (b), $46.4 \pm 1.1 \mathrm{~mm}$ (a) x $33.0 \pm 1.4 \mathrm{~mm}$ (b) and $48.8 \pm 0.8 \mathrm{~mm}$ (a) $\mathrm{x}$ $33.8 \pm 1.3 \mathrm{~mm}$ (b), respectively.

A significant difference was observed between no flow and saline infusion (Fig. 4). However, multiple comparisons of the range of coagulation revealed no significant differences between flow rates of 3,4 and $5 \mathrm{ml} / \mathrm{min}$ at a microwave output of $80 \mathrm{~W}$ (Fig. 4). Therefore, a flow rate of at least $3 \mathrm{ml} / \mathrm{min}$ was selected as the irradiation setting for coagulation in the in vivo porcine liver. Moreover, when compared with the no-flow condition, the carbonization of the tissue surrounding the electrode was suppressed significantly by injecting physiological saline (Fig. 5).

Range of coagulation in in vivo porcine liver using PME or $R F A$. When the in vivo porcine liver was coagulated using the 


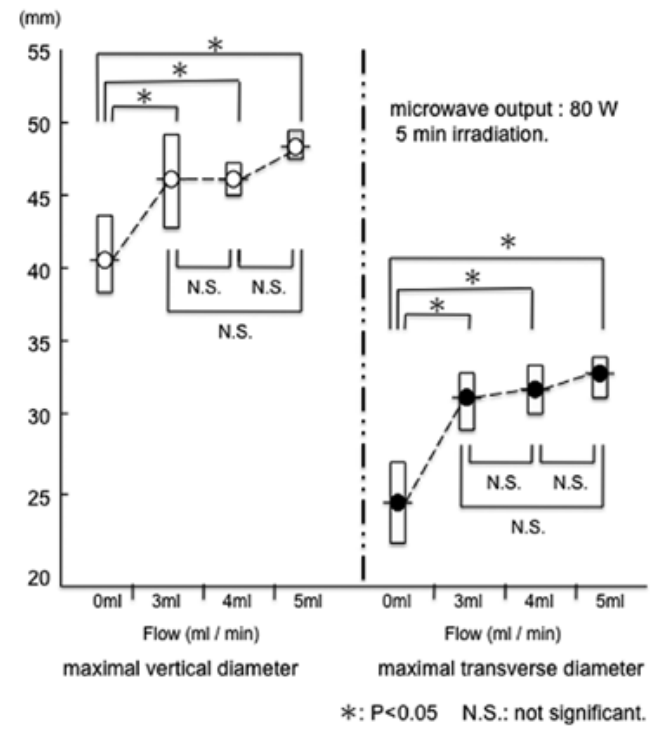

Figure 4. At $80 \mathrm{~W}$ for $5 \mathrm{~min}$ irradiation, the range of coagulation increased when physiological saline was injected. Multiple comparisons of the ranges of coagulation showed no significant differences among flow rates of 3,4 and $5 \mathrm{ml} / \mathrm{min}$.

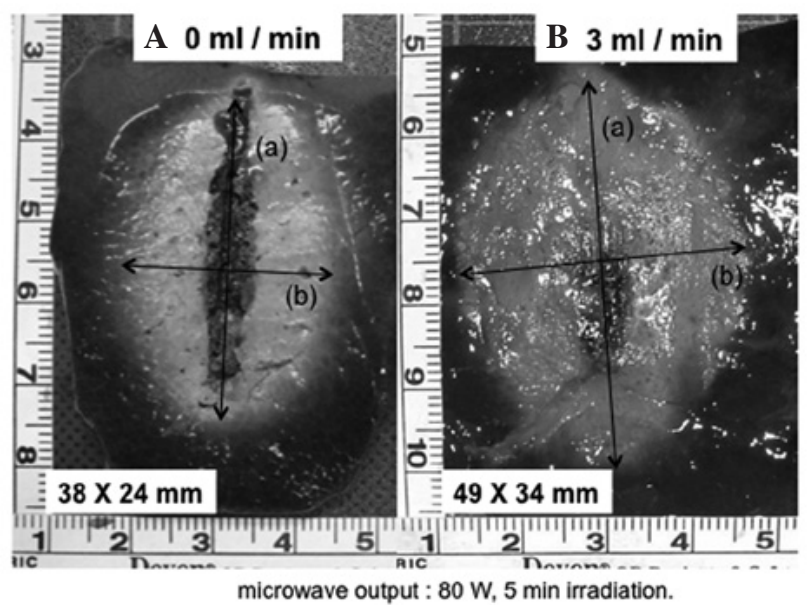

(a) : maximal vertical diameter

(b) : maximal transverse diameter

Figure 5. Gross appearance of the coagulated area of ex vivo bovine liver treated with the PME at $80 \mathrm{~W}$ for 5 min microwave irradiation (A) $0 \mathrm{ml} / \mathrm{min}$. (B) $3 \mathrm{ml} / \mathrm{min}$. Compared with the no-flow condition, the carbonization of the tissue surrounding the electrode was suppressed significantly by injecting the physiological saline. PME, perfusion microwave electrode.

PME under conditions of a microwave output of $80 \mathrm{~W}, 5 \mathrm{~min}$ irradiation, and a flow rate of $3 \mathrm{ml} / \mathrm{min}$, the range of coagulation was $44.8 \pm 2.8 \mathrm{~mm}$ (a) $\times 31.2 \pm 2.4 \mathrm{~mm}$ (b). The range of PME coagulation was compared between the result of the experiment using the ex vivo bovine liver (microwave output, $80 \mathrm{~W}$; flow rate, $3 \mathrm{ml} / \mathrm{min}$ ) and that of the experiment using the in vivo porcine liver. As shown in Fig. 6, no significant difference in the range of PME coagulation was evident between the ex vivo bovine liver $[46.4 \pm 3.0 \mathrm{~mm}$ (a) $\mathrm{x} 32.2 \pm 1.8 \mathrm{~mm}$ (b)] and the in vivo porcine liver.

The range of RFA for $5 \mathrm{~min}$ in the in vivo porcine liver was $34.6 \pm 2.4 \mathrm{~mm}$ (a) x $18.6 \pm 0.9 \mathrm{~mm}$ (b). Under 5 min treat-

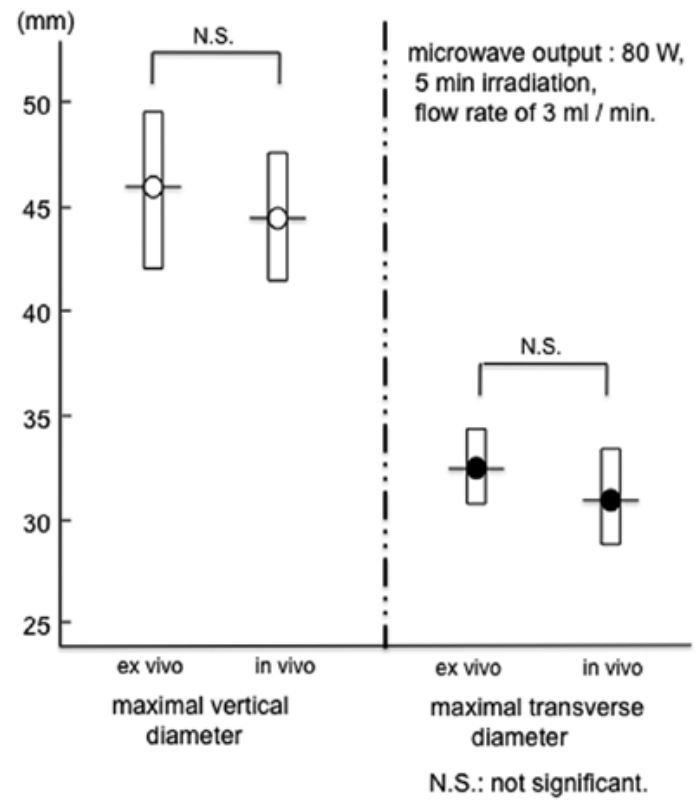

Figure 6. The range of PME coagulation was compared between the experiment using an ex vivo bovine liver (microwave output at $80 \mathrm{~W}, 5 \mathrm{~min}$ irradiation, flow rate of $3 \mathrm{ml} / \mathrm{min}$ ) and the experiment using an in vivo porcine liver. No significant difference was evident between these two livers. PME, perfusion microwave electrode.

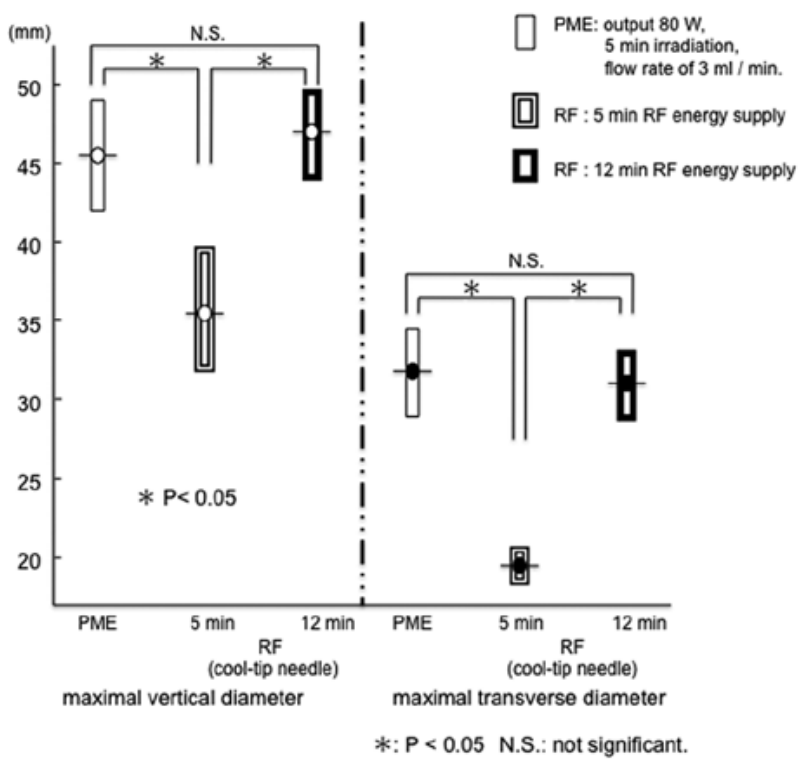

Figure 7. In the in vivo porcine liver, the range of ablation by RFA was smaller than that by the PME with 5-min treatment. Conversely, the same range of coagulation obtained by PME for 5 min could be achieved by RFA in $12 \mathrm{~min}$. PME, perfusion microwave electrode; RFA, radiofrequency ablation.

ment, both the maximal vertical diameter and maximal transverse diameter were larger with PME than RFA (Fig. 7). Conversely, the range of RFA for $12 \mathrm{~min}$ was $46.0 \pm 2.0 \mathrm{~mm}$ (a) x $30.2 \pm 2.0 \mathrm{~mm}$ (b). This range did not differ from that of PME coagulation under the conditions of a microwave output of $80 \mathrm{~W}, 5 \mathrm{~min}$ irradiation, and a flow rate of $3 \mathrm{ml} / \mathrm{min}$ (Figs. 7 and 8). In the in vivo porcine liver, the same range of coagulation obtained by RFA for 12 min could be produced by the PME over 5 min of microwave irradiation. 


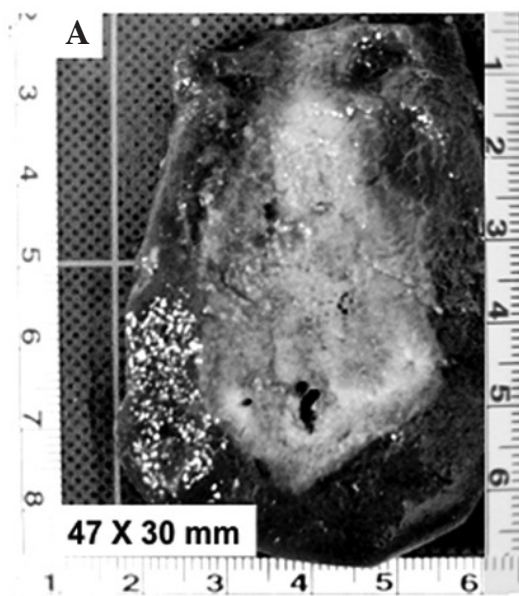

PME : output $80 \mathrm{~W}, 5$ min irradiation, flow rate of $3 \mathrm{ml} / \mathrm{min}$.

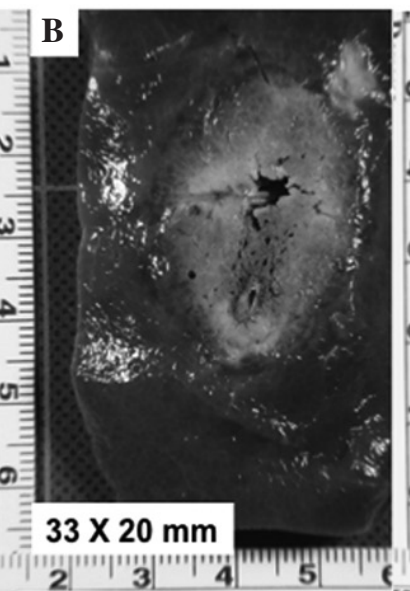

RF : 5 min RF energy supply.

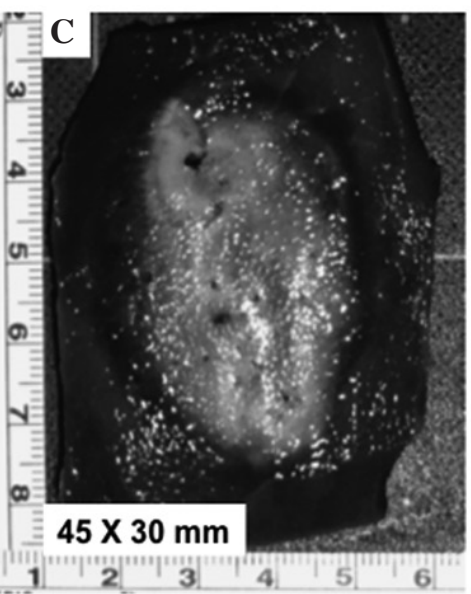

RF : 12 min RF energy supply.

Figure 8. Gross appearance of the coagulated area in the in vivo porcine liver treated with the (A) PME, (B) RFA for 5 min and (C) RFA for 12 min. RFA, radiofrequency ablation; PME, perfusion microwave electrode.

\section{Discussion}

The microwave tissue coagulation system developed by Tabuse has mainly been used during surgery $(16,17)$. Subsequently, a microwave electrode for percutaneous insertion was developed by Seki et al (7) and used for ultrasonically guided percutaneous coagulation therapy for HCC (7-11) and metastatic liver cancer $(9,11)$. Thereafter, laparoscopic microwave coagulation therapy under local anesthesia was reported as a minimally invasive and effective therapy for HCC that is located near the hepatic surface $(18,19)$. Microwave coagulation therapy has come to be recognized as a reliable thermal ablation procedure for liver cancer. Shibata et al conducted a randomized controlled trial to compare the two techniques for treating small HCCs and found that PMCT and PRFA were equivalent in local therapeutic efficacy, complication rates and local recurrence rates (20). However, the range of coagulation obtained with a single electrode was smaller than that obtained by RFA, a method that was subsequently developed. This is currently the major mode for local cancer treatments (12-14). In addition, various methods are being developed to increase the range of microwave coagulation $(21,22)$. Against this background, the present study was performed to evaluate the coagulation capability of a new type of microwave electrode (a PME) and to compare the coagulation capability between the PME and RFA electrodes (cool-tip needle).

Microwave tissue coagulation is defined as a mode of thermal coagulation that uses heat from friction (dielectric heating), which is generated when polar molecules (those of water in the body) vibrate markedly in response to microwave irradiation $(7,10)$. If a conventional electrode is used, the surrounding tissues will be coagulated due to a rise in temperature (dielectric heating) caused by microwave irradiation. However, the tissue near the electrode will be carbonized owing to a rapid rise in temperature. In this situation, the delivery of microwave energy may be attenuated by the presence of carbonized tissue or its adherence to the electrode. As a result, the range of stable heating is limited.
Therefore, in the present study, a new type of microwave electrode was designed so that physiological saline could be injected continuously through it. This electrode is known as a PME. Physiological saline was injected continuously to inhibit a rapid increase of temperature at the tip of the electrode and to prevent tissue carbonization. The attenuation of microwave energy delivered due to the presence of carbonized tissue or its adherence to the electrode is averted and the microwave energy is delivered efficiently. As a result, it is thought that the coagulation range is expanded. In addition, the temperature rise of the injected physiological saline itself, by microwave irradiation, may also be related to an increase in the coagulation range.

In actuality, the carbonization of the electrode by the surrounding tissue was significantly suppressed by injecting the physiological saline and the range of coagulation was augmented in the experiment with the ex vivo bovine liver.

During microwave irradiation, the tip of the PME maintained a temperature sufficiently high for tissue coagulation, while an excessive rise in the temperature of the electrode shaft ( $5 \mathrm{~cm}$ from the tip) was inhibited by increasing the volume of the injected physiological saline. Therefore, the risk of skin burns should be reduced by clinical application of this electrode.

In the experiment using in vivo liver, the coagulation conditions were set on the basis of results obtained in the experiment in which an ex vivo bovine liver was used. The microwave output was set at $80 \mathrm{~W}$ since the range of coagulation increased with an increase in the microwave output from 60 to $80 \mathrm{~W}$.

When the flow rate of the physiological saline was low ( 1 or $2 \mathrm{ml} / \mathrm{min}$ ), the injection port at the tip of the electrode was sometimes occluded by the carbonization of tissue around the tip and adherence of coagulated tissue to the electrode, interfering with the injection of physiological saline. When it exceeded $6 \mathrm{ml} / \mathrm{min}$, it became unsuitable due to saline overflow from the insertion line. Thus, the ex vivo bovine liver was coagulated at a flow rate of a few $\mathrm{ml}$ of saline (3, 4 or $5 \mathrm{ml} / \mathrm{min})$. 
In reality, the range of coagulation may be augmented by injecting the physiological saline at $80 \mathrm{~W}$ for $5 \mathrm{~min}$. However, multiple comparisons of the range of coagulation displayed no significant differences between flow rates of 3,4 and $5 \mathrm{ml} / \mathrm{min}$. This fact demonstrated that a flow rate of $3 \mathrm{ml} / \mathrm{min}$ was sufficient to prevent tissue carbonization or its adherence to the electrode at $80 \mathrm{~W}$ output for $5 \mathrm{~min}$. A flow rate of at least $3 \mathrm{ml} / \mathrm{min}$ was selected as being most efficient in this study.

In the experiment using in vivo porcine liver, when the microwave output was $80 \mathrm{~W}$, irradiation time was $5 \mathrm{~min}$ and flow rate was $3 \mathrm{ml} / \mathrm{min}$, the range of coagulation was similar to that observed in the ex vivo bovine liver under the same conditions. This result indicates that tissue coagulation using the PME may be achieved efficiently in spite of the presence of a cooling effect caused by blood flow. This suggests that the influence of tissue blood flow on coagulation is slight when this system is used. However, this was a preliminary study. Further investigation will be required to search for the best coagulation setting for the PME, such as microwave output and irradiation time.

Since the range of coagulation obtained with a single electrode is wider using RFA than microwave coagulation therapy (MCT) using the existing electrode, RFA is widely performed at present as a local ablation therapy. In the present study, the PME and a single-needle RF electrode (cool-tip needle), which is currently used at many medical institutions, were compared for their ranges of coagulation. We confirmed that the same range of coagulation obtained by the cool-tip needle under ordinary conditions (maximum output, treatment for $12 \mathrm{~min}$ ) may be obtained by the PME within a much shorter period (5 min). Rapid-term treatment is important in clinical applications to minimize the stress on patients and operators. Moreover, rapid-term treatment may reduce the frequency of complications. Further experimental studies under various coagulation settings (e.g., power output and irradiation time) will be necessary to determine whether the coagulation ability of PME is superior to that of RFA (cool-tip needle). Furthermore, a microwave electrode having an internally cooled shaft antenna was recently developed and used clinically (22). It was reported that the range of coagulation was $54 \pm 5$ (long axis) x $36 \pm 4 \mathrm{~mm}$ (short axis), when the in vivo porcine liver was coagulated using the cooled shaft antenna under conditions of a microwave output of $80 \mathrm{~W}$, for $5 \mathrm{~min}$. Therefore, a comparison study is necessary between the PME and the cooled shaft antenna.

During clinical application, one may fear that the PME could cause cancer cell seeding since physiological saline is injected into the tumor. Because the cancerous tissue around the electrode tip coagulates immediately upon initiating microwave irradiation and the temperature of the injected physiological saline is raised markedly by the microwaves, the possibility of seeding cancer cells is thought to be low. On this point, further studies using a tumor model are required $(23,24)$.

The HITT 106 system, an RF electrode designed to increase the range of coagulation by injecting physiological saline (at a flow rate of $38-120 \mathrm{ml} / \mathrm{h}$ ) during the application of RF energy, has already been developed and used clinically $(25,26)$, with no data presented on increased cancer cell dispersion or metastasis (27). Thus, comparison research on the PME and saline perfusion RFA systems will be necessary.
In conclusion, the PME increases the range of tissue coagulation by infusion of saline into the target tissues. In in vivo porcine liver, the same range of coagulation obtained by RFA (cool-tip needle) for 12 min may be produced with the PME by $5 \mathrm{~min}$ of microwave treatment. We believe that the PME produces effective treatment results in a short time and is one of the tissue coagulation systems suitable for local ablation therapy.

\section{References}

1. Tobe T, Uchino J, Endo Y, Oto M, Okamoto E, Kojiro M, Shikata T, Tanikawa K, Tsuzuki T, Mizumoto R, Mito M, Yamada R, Arii S and Hiraishi Y: Percutaneous ethanol injection therapy for hepatocellular carcinoma: predictive factors for long-term prognosis after partial hepatectomy for patients with hepatocellular carcinoma in Japan. Cancer 74: 2772-2780, 1994.

2. Shiina S, Tagawa K, Niwa Y, Unuma T, Komatsu Y, Yoshiura K, Hamada E, Takahashi M, Shiratori Y and Terano A: Percutaneous ethanol injection therapy for hepatocellular carcinoma: results in 146 patients. AJR Am J Roentgenol 160: 1023-1028, 1993.

3. Kotoh K, Sakai H, Sakamoto S, Kotoh K, Sakai H, Sakamoto S, Nakayama S, Satoh M, Morotomi I and Nawata H: The effect of percutaneous ethanol injection therapy on small solitary hepatocellular carcinoma is comparable to that of hepatectomy. Am J Gastroenterol 89: 194-198, 1994.

4. Livraghi T, Giorgio A, Marin G, A Salmi A, de Sio I, Bolondi L, Pompili M, Brunello F, Lazzaroni S and Torzilli G: Hepatocellular carcinoma and cirrhosis in 746 patients: long-term results of percutaneous ethanol injection. Radiology 197: 101-108, 1995.

5. Seki T, Nonaka T, Kubota Y, Mizuno T and Sameshima Y: Ultrasonically guided percutaneous ethanol injection therapy for hepatocellular carcinoma. Am J Gastroenterol 84: 1400-1407, 1989.

6. Shiina S, Tagawa K, Unuma T, Takanashi R, Yoshiura K, Komatsu Y, Hata Y, Niwa Y, Shiratori Y, Terano A and Sugimoto T: Percutaneous ethanol injection therapy for hepatocellular carcinoma: a histopathologic study. Cancer 68: 1524-1530, 1991

7. Seki T, Wakabayashi M, Nakagawa T, Itho T, Shiro T, Kunieda K, Sato M, Uchiyama S and Inoue K: Ultrasonically guided percutaneous microwave coagulation therapy for small hepatocellular carcinoma. Cancer 74: 817-825, 1994.

8. Murakami R, Yoshimatsu S, Yamashita Y, Matsukawa T, Takahashi M and Sagara K: Treatment of hepatocellular carcinoma: value of percutaneous microwave coagulation. AJR Am J Roentgenol 164: 1159-1164, 1995.

9. Sato M, Watanabe Y, Kashu Y, Nakata T, Hamada Y and Kawachi K: Sequential percutaneous microwave coagulation therapy for liver tumor. Am J Surg 175: 322-324, 1998.

10. Seki T, Wakabayashi M, Nakagawa T, Imamura M, Tamai T, Nishimura A, Yamashiki N, Okamura A and Inoue K: Percutaneous microwave coagulation therapy for patients with small hepatocellular carcinoma: comparison with percutaneous ethanol injection therapy. Cancer 85: 1694-1702, 1999.

11. Matsukawa T, Yamashita Y, Arakawa A, Nishiharu T, Urata J, Murakami R, Takahashi M and Yoshimatsu S: Percutaneous microwave coagulation therapy in liver tumors: a 3-year experience. Acta Radiol 38: 410-415, 1997.

12. Rossi S, Fornari F and Buscarini L: Percutaneous ultrasoundguided radiofrequency electrocautery for the treatment of small hepatocellular carcinoma. J Intervent Radiol 8: 97-103, 1993.

13. Livraghi T, Goldberg SN, Lazzaroni S, Meloni F, Solbiati L and Gazelle GS: Small hepatocellular carcinoma: treatment with radio-frequency ablation versus ethanol injection. Radiology 210 : 655-661, 1999.

14. Livraghi T,Goldberg S,LazzaroniS,MeloniF, TiIerace T, SolbiatiL and Gazelle GS: Hepatocellular carcinoma: radio-frequency ablation of medium and large lesions. Radiology 214: 761-768, 2000.

15. Sugimori K, Nozawa A, Morimoto M, Shirato K, Kokawa A, Saito T, Numata K and Tanaka K: Extension of radiofrequency ablation of the liver by transcatheter arterial embolization with iodized oil and gelatin sponge: results in a pig model. J Vasc Interv Radiol 16: 849-856, 2005.

16. Tabuse K: A new operative procedure of hepatic surgery using a microwave tissue coagulator. Nihon Geka Hokan 48: 160-172, 1979. 
17. Tabuse K: Basic knowledge of a microwave tissue coagulator and its clinical applications. J Hepatobiliary Pancreat Surg 5: 165-172, 1998.

18. Seki S, Sakaguchi H, Kadoya H, Morikawa H, Habu D, Nishiguchi S, Shiomi S, Kitada T and Kuroki T: Laparoscopic microwave coagulation therapy for hepatocellular carcinoma. Endoscopy 32: 591-597, 2000.

19. Seki S, Sakaguchi H, Iwai S, Kadoya H, Kabayashi S, Kitada T, Fujii $\mathrm{H}$ and Tanaka T: Five-year survival of patients with hepatocellular carcinoma treated with laparoscopic microwave coagulation therapy. Endoscopy 37: 1220-1225, 2005.

20. Shibata T, Iimuro Y, Yamamoto Y, Maetani Y, Ametani F, Itoh K and Konishi J: Small hepatocellular carcinoma: comparison of radio-frequency ablation and percutaneous microwave coagulation therapy. Radiology 223: 331-337, 2002.

21. Shock SA, Meredith K, Warner TF, Sampson LA, Wright AS, Winter TC III, Mahvi DM, Fine JP and Lee FT Jr: Microwave ablation with loop antenna: in vivo porcine liver model. Radiology 231: 143-149, 2004.

22. Kuang M, Lu MD, Xie XY, Xu HX, Mo LQ, Liu GJ, Xu ZF, Zheng YL and Liang JY: Liver cancer increased microwave delivery to ablation zone with cooled-shaft antenna - experimental and clinical studies. Radiology 242: 914-924, 2007.
23. Miao Y, Ni Y, Mulier S, Yu J, De Wever I, Penninckx F, Baert AL and Marchal G: Treatment of VX2 liver tumor in rabbits with 'Wet' electrode mediated radio-frequency ablation. Eur Radiol 10: 188-194, 2000.

24. Hines-Peralta A, Liu ZJ, Horkan C, Solazzo S and Goldberg SN: Chemical tumor ablation with use of a novel multiple-tine infusion system in a canine sarcoma model. J Vasc Interv Radiol 17: 1351-1358, 2006.

25. Schmidt D, Trübenbach J, Brieger J, Koenig C, Putzhammer H, Duda SH, Claussen CD and Pereira PL: Automated saline-enhanced radiofrequency thermal ablation: initial results in ex-vivo bovine liver. AJR Am J Roentgenol 180: 163-165, 2003.

26. Pereira PL, Trübenbach J, Schenk M, Subke J, Kroeber S, Schaefer I, Remy CT, Schmidt D, Brieger J and Claussen CD: Radiofrequency ablation: in vivo comparison of four commercially available devices in pig livers. Radiology 232: 482-490, 2004.

27. Hänsler J, Frieser M, Tietz V, Uhlke D, Wissniowski T, Bernatik T, Hothorn T, Hahn EG and Strobel D: Percutaneous radiofrequency ablation of liver tumors using multiple saline-perfused electrodes. J Vasc Interv Radiol 18: 405-441, 2007. 